\section{P139 ATELECTASIS FOLLOWING BRONCHOSCOPIC LUNG VOLUME REDUCTION (BLVR) IS ASSOCIATED WITH IMPROVED SURVIVAL IN COPD}

doi:10.1136/thx.2010.150987.40

N S Hopkinson, S V Kemp, T P Toma, D M Hansell, D M Geddes, P L Shah, M I Polkey. NIHR Respiratory Disease Biomedical Research Unit at the Royal Brompton and Harefield NHS Foundation Trust and Imperial College London, London, UK

Background A range of bronchoscopic therapies are being developed to reduce lung volumes in COPD patients, either in order to avoid the morbidity and mortality associated with lung volume reduction surgery, or to extend therapy to patient groups in whom LVRS is not appropriate because of disease pattern or severity.

Aims Bronchoscopic lung volume reduction (BLVR), using endobronchial valves to target unilateral lobar occlusion in patients with heterogeneous emphysema has been shown to improve lung function and exercise capacity in patients with emphysema. Benefit was most pronounced in, though not confined to, patients where lobar atelectasis occurred. Little data exists on the long-term outcome following BLVR.

Study population 19 patients (16 males) $\mathrm{FEV}_{1} 28.4$ (11.9) underwent BLVR between July 2002 and February 2004. Radiological atelectasis was observed in five patients. Survival data to February 2010 was available for all patients. The age dyspnoea obstruction (ADO) score was used to calculate predicted mortality.

Results None of the patients in whom atelectasis occurred died during follow up whereas eight out of 14 in the non-atelectasis group died $\left(\chi^{2} \mathrm{p}=0.026\right)$ (Abstract P139 Figure 1). There was no significant difference between the groups at baseline in lung function, quality of life, exacerbation rate, exercise capacity (shuttle walk test or cycle ergometry) or CT appearances, although BMI was significantly higher in the atelectasis group 21.6(2.9) vs $28.4(2.9) \mathrm{kg}$. $\mathrm{m}^{-2} \quad(\mathrm{p}<0.001)$. Pre treatment CT appearances did not differ significantly between the atelectasis and non-atelectasis groups in terms of degree of emphysema at either the upper or lower parts of the lungs or in heterogeneity (slope) in either the treated or nontreated lung prior to treatment. $\mathrm{ADO}$ score, predicted 3 year mortality was $31.1(10.0) \%$ in the non-atelectasis group and 32.2 $(15.1) \%$ in the atelectasis group $(p=0.8)$. Four of the eight deaths occurred within 3 years of the procedure, representing a $29 \%$ mortality rate for the non-atelectasis group (ie, close to that predicted).

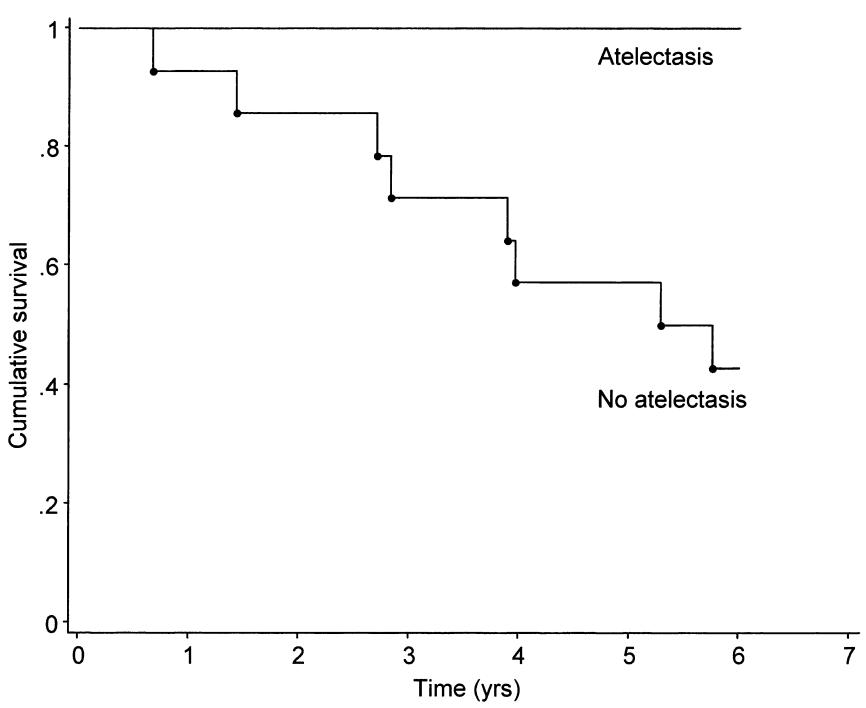

Abstract P139 Figure 1
Conclusions These data suggest that atelectasis following BLVR is associated with a survival benefit which is not explained by differences at baseline.

\section{REFERENCE}

1. Hopkinson, et al. AJRCCM 2005;453-60.

\section{P140 THORACOSCOPIC BULLECTOMY FOR DYSPNOEA IN EMPHYSEMA: DEFINING NEW BOUNDARIES}

doi:10.1136/thx.2010.150987.41

D S Stavroulias, K L Lau, I 0 Oey, A N Nakas, S R Rathinam, D A W Waller Department of Thoracic Surgery of Glenfield Hospital, Leicester, UK

Objectives There exists only limited historical guidance on patient selection for giant bullectomy in emphysema which is now 20years-old (1). Operative mortality was reported at about $10 \%$, and patients with $\mathrm{FEV}_{1}<50 \%$ predicted were excluded. Developments in video assisted thoracic surgery (VATS) and experience with lung volume reduction surgery have reduced our selection threshold. We have reviewed our results in the last decade and their implications for patient selection.

Methods Between June 1997 and November 2009, 55 patients (45 males:10 females; median age 61 years (range 39-76 years)) with significant dyspnoea associated with giant emphysematous bullae underwent surgery. Their median preoperative $\mathrm{FEV}_{1}$ was $31 \%$ predicted (range 9-93\%). Twenty nine patients had $\mathrm{FEV}_{1}<50 \%$ pred and fifteen $<25 \%$ pred. Eight patients were in type I respiratory failure three patients had alpha-1-antitrypsin deficiency. All were cigarette smokers and four had significant cannabis use. In all patients there was evidence of hyperinflation and a bulla occupying $>30 \%$ of the hemithorax. All operations were performed by stapled VATS bullectomy and in the high risk patients six operations were performed under sedation with spontaneous ventilation and two using intraoperative extracorporeal membrane oxygenation (ECMO).

Results Median hospital stay was 9 days (range 3-64 days). Prolonged air leak (lasting over $48 \mathrm{~h}$ ) was observed in 21 patients $(38 \%)$. Three patients $(6 \%)$ required postoperative ventilation. 30 day mortality was $3.6 \%$ (two patients). One-year survival was $94.5 \%$ (52 patients). Symptomatic improvement in dyspnoea was reported in $73 \%$ patients.

Conclusions VATS bullectomy should be considered for symptom relief even in patients with severe airflow obstruction and borderline respiratory failure.

\section{REFERENCE}

1. Kinnear WJM, Tattersfield AE. Emphysematous bullae: surgery is best for large bullae and moderately impaired lung function. BMJ 1990;300:2008-9.

\section{P141 LUNG VOLUME REDUCTION SURGERY-THE FIRST 200 OPERATIONS IN A UK CENTRE: THE BENEFITS OF A MULTIDISCIPLINARY STRATEGY AND MINIMALLY INVASIVE APPROACH}

doi:10.1136/thx.2010.150987.42

K A Abdul Aziz, I F Oey, D A Waller, M D Morgan, M C Steiner, S J Singh. Glenfield Hospital, Leicester, UK

Objective Despite the supportive results of the randomised, controlled NETT trial, lung volume reduction surgery (LVRS) is still 


\section{REFERENCES}

1. Ferguson KA, Cartwright $R$, Rogers $R$, et al. Oral appliances for snoring and obstructive sleep apnea: a review. Sleep 2006;29:244-62.

2. Mehta A, Qian J, Petocz P, et al. A randomized, controlled study of a mandibular advancement splint for obstructive sleep apnea. Am J Respir Crit Care Med 2001;163:1457-61.

3. Barnes M, McEvoy RD, Banks S, et al. Efficacy of positive airway pressure and oral appliance in mild to moderate obstructive sleep apnea. Am J Respir Crit Care Med 2004;170:656-64.

4. Gagnadoux F, Fleury B, Vielle B, et al. Titrated mandibular advancement versus positive airway pressure for sleep apnoea. Eur Respir J 2009:34:914-20.

5. Marklund M, Stenlund H, Franklin KA. Mandibular advancement devices in 630 men and women with obstructive sleep apnea and snoring: tolerability and predictors of treatment success. Chest 2004;125:1270-8.

6. Henke KG, Frantz DE, Kuna ST. An oral elastic mandibular advancement device for obstructive sleep apnea. Am J Respir Crit Care Med 2000;143:942-6.

7. Sanner BM, Heise M, Knoben B, et al. MRI of the pharynx and treatment efficacy of a mandibular advancement device in obstructive sleep apnoea syndrome. Eur Respir $\mathrm{J}$ 2002;20:143-50.

8. $\quad \mathbf{N g}$ AT, Qian J, Cistulli PA. Oropharyngeal collapse predicts treatment response with oral appliance therapy in obstructive sleep apnea. Sleep 2006;29:666-71.

9. Sériès $\mathbf{F}$, Strauss $\mathbf{C}$, Demoule $A$, et al. Assessment of upper airway dynamics in awake sleep apnea patients with phrenic nerve stimulation. Am J Respir Crit Care Med 2000;162:795-800.

10. Verin E, Similowski T, Teixeira A, et al. Discriminative power of phrenic twitchinduced dynamic response for diagnosis of sleep apnea during wakefulness. $J$ Appl Physiol 2003:94:31-7.

11. Vérin $\mathbf{E}$, Similowski T, Series F. Effects of continuous positive airway pressure on upper airway inspiratory dynamics in awake patients with sleep-disordered breathing J Physiol 2003;546:279-87.

12. Sériès $\mathbf{F}$, Ethier $\mathrm{G}$. Site of phrenic nerve stimulation-induced upper airway collapse: influence of expiratory time. J Appl Physiol 2002;92:665-71.

13. Wang W, Verin E, Sériès F. Influences of the breathing route on upper airway dynamics properties in normal awake subjects with constant mouth opening. Clin Sci (Lond) 2006;111:349-55

14. Anon. Sleep-related breathing disorders in adults. recommendations for syndrome definition and measurement techniques in clinical research. The Report of an American Academy of Sleep Medicine Task Force. Sleep 1999;22:667-89.
15. Kyroussis D, Hamnegard $\mathrm{CH}$, Polkey Ml, et al. Bilateral magnetic stimluation of the phrenic nerves from an anterolateral approach. Am J Respir Crit Care Med 1996:153:1880-7.

16. Fleury B, Rakotonanahary D, Petelle B, et al. Manidbular advancement titration for obstructive sleep apnea. Chest 2004;125:1761-7.

17. Zeng B, Ng AT, Darendellier MA, et al. Use of flow-volume curves to predict ora appliance treatment outcome in obstructive sleep apnea. Am J Respir Crit Care Med 2007; 175:726-30.

18. Gotsopoulos H, Kelly JJ, Cistulli PA. Oral appliance therapy reduces blood pressure in obstructive sleep apnea: a randomized, controlled trial. Sleep 2004;27: 934-41.

19. Itzhaki S, Dorchin H, Clark G, et al. The effects of 1 year treatment with a Herbst mandibular advancement splint on obstructive sleep apnea, oxidative stress, and endothelial function. Chest 2007:131:740-9.

20. Isono S, Tanaka $A$, Tagaito $Y$, et al. Pharyngeal patency in response to advancement of the mandible in obese anesthetized persons. Anesthesiology 1997;87:1055-62.

21. Johal A, Battagel JM, Kotecha BT. Sleep nasendoscopy: a diagnostic tool for predicting treatment success with mandibular advancement splints in obstructive sleep apnoea. Eur J Orthod 2005;27:607-14.

22. Otsuka R, de Almeida FR, Lowe A, et al. A comparison of responders and nonresponders to oral appliance therapy for the treatment of obstructive sleep apnea. Am J Orthod Dentofacial Orthop 2006;129:222-9.

23. De Backer JW, Vanderveken OM, Vos WG, et al. Functional imaging using computational fluid dynamics to predict treatment success of mandibular advancement devices in sleep-disordered breathing. J Biomech 2007;40:3708-14

24. Chan AS, Lee RW, Srinivasan VK, et al. Nasopharyngoscopic evaluation of oral appliance therapy for obstructive sleep apnoea. Eur Respir $J$ 2010;35:836-42.

25. Chan AS, Lee RW, Srinivasan VK, et al. Use of flow-volume curves to predict ora appliance treatment outcome in obstructive sleep apnea: a prospective validation study. Sleep Breath Published Online First: 2010 Jul 29. doi:10.1007/s11325-010-0395-7.

26. Verin $\mathbf{E}$, Petelle $\mathrm{B}$, Raux $\mathrm{M}$, et al. Effects of mandibular advancement on upper airway dynamics in awake normal subjects: a pilot study with phrenic nerve stimulation. Sleep Med 2006;7:368-73.

27. Chan AS, Sutherland K, Schwab RJ, et al. The effect of mandibular advancement on upper airway structure in obstructive sleep apnoea. Thorax 2010;65:726-32

\section{Correction}

D S Stavroulias, K L Lau, I O Oey, et al. Thoracoscopic bullectomy for dyspnoea in emphysema: defining new boundaries. Thorax 2010;65:A137. The authors names appeared incorrectly in this abstract. The names should have appeared as follows: D Stavroulias, K Lau, I Oey, A Nakas, S Rathinam, D A Waller.

Thorax 2011:66:225. doi:10.1136/thx.2010.150987.41corr1 